\title{
The impact of athletic clothing style and body awareness on motor performance in women
}

\author{
Elizabeth Cox $^{1} \cdot$ Catherine M. Sabiston ${ }^{2} \cdot$ April Karlinsky $^{3} \cdot$ Joseph Manzone ${ }^{3} \cdot$ Heather F. Neyedli $^{4}$. \\ Timothy N. Welsh ${ }^{3}$
}

Published online: 4 June 2020

(C) The Psychonomic Society, Inc. 2020

\begin{abstract}
The type of clothing worn, revealing versus concealing, can affect the performance of women on cognitive tasks. This difference in performance may arise because of changes in body awareness that may draw cognitive resources from the goal task. The present study investigated the influence of the style of athletic clothing and body awareness on visual-motor performance in women. Participants (women ages 18-35 years) were randomly assigned to wear tight and revealing (TR group, $n=40$ ) or loose and concealing (LC group, $n=40$ ) athletic clothing. All participants completed the same visual-motor aiming task to assess spatiotemporal measures of motor performance. In addition to the clothing, participants were primed to be conscious of their bodies via measurements of height, weight, and waist circumference; photographs taken of their bodies; a computerized bodysize distortion task; and a mirror in the testing chamber. Results revealed that the TR group had increased movement time variability and did not show performance improvements relative to the LC group. These differences suggest that style of clothing may influence motor performance in women by reallocating cognitive resources towards the body and away from the motor task at hand. This research highlights the interactions between cognitive and motor processes and, potentially, the importance of considering the impact of clothing on performance in many different contexts.
\end{abstract}

Keywords Body consciousness $\cdot$ Cognitive resources $\cdot$ Motor planning $\cdot$ Clothing comfort

There is evidence that women who are more aware of their bodies perform worse on cognitive tasks than those who are less aware of their bodies (Fredrickson, Roberts, Noll, Quinn, \& Twenge, 1998; Gay \& Castano, 2010; Gervais, Vescio, \& Allen, 2011; Hebl, King, \& Lin, 2004; Kahalon, Shnabel, \& Becker, 2018; Quinn, Kallen, Twenge, \& Fredrickson, 2006). For example, compared with women wearing loose and

Timothy N. Welsh

t.welsh@utoronto.ca

1 Department of Psychology, Faculty of Arts \& Science, University of Toronto, Toronto, Ontario, Canada

2 Mental Health and Physical Activity Research Centre, Faculty of Kinesiology \& Physical Education, University of Toronto, Toronto, Ontario, Canada

3 Centre for Motor Control, Faculty of Kinesiology \& Physical Education, University of Toronto, 55 Harbord Street, Toronto, Ontario, Canada

4 Kinesiology, School of Health and Human Performance, Dalhousie University, Halifax, Nova Scotia, Canada concealing clothing (e.g., a sweater), women wearing tight and revealing clothing (e.g., a swimsuit) perform worse on tasks that demand a greater allocation of cognitive resources, including tests of working memory, attention, and academic achievement (Fredrickson et al., 1998; Hebl et al., 2004; Quinn et al., 2006). Because wearing tight and revealing clothing predicts greater body-related awareness and selfconscious emotions in women than wearing loose and concealing clothing, these deficits in cognitive performance have been attributed to a greater allocation of limited cognitive resources towards the body that in turn reduces resources available to process task-related information (Fredrickson et al., 1998).

Based on these findings and the proposed reciprocal interconnections between cognitive and motor processing (e.g., see Hommel et al., 2019), it is plausible that the relation between clothing style, body awareness, and performance extends to motor tasks. Hence, a paradoxical situation may arise in which clothing that may be designed to increase freedom of movement and range of motion (e.g., tight-fitting tank tops, short shorts, bathing suits) may actually have a negative effect on 
performance due to increased body awareness and an associated decrease in available resources for motor preparation and execution. Although no specific study has examined this relation between clothing and motor performance, there is related evidence from previous research that is consistent with this hypothesis. First, an "internal" focus on the body and body motion impedes skilled motor learning and performance relative to an "external" focus on the environment or the effect of the action (see Wulf, 2013, for a review). Second, increased body-related self-conscious emotions (elicited by answering written questions about their bodies) disrupt throwing performance in girls (Fredrickson \& Harrison, 2005). Although the findings suggest that women's internal focus on the body reduces performance on cognitive tasks (Fredrickson et al., 1998; Hebl et al., 2004; Quinn et al., 2006), to our knowledge, no study has specifically examined how differences in body awareness due to athletic clothing influences visual-motor performance in women.

This influence of clothing on cognitive and motor performance is an important issue for both theoretical and practical reasons. On the theoretical level, evidence for an influence of body awareness on motor performance would support the notion of a highly interconnected sensori-cognitive-motor system (e.g., Hommel et al., 2019). On the practical level, determining the influence of athletic clothing style on emotions and cognitive-motor performance could provide valuable knowledge to inform strategies to increase motor performance and learning, as well as motivation for continuing in behaviors like physical activity. This issue of performance, learning, and motivation is important because women who are more aware of their bodies also report engaging in activities such as weight training, running/walking, and ball sports less frequently than do women who report lower body awareness (Melbye, Tenenbaum, \& Eklund, 2007). Furthermore, women are less active than men across the life span (Guthold, Stevens, Riley, $\&$ Bull, 2018), and the social construction of the body and cognitive resources linked to body awareness may in part explain gender discrepancies in participation in many activities (Fredrickson et al., 1998; Parsons \& Betz, 2001; Quinn et al., 2006). Considering the wide variety of clothing available to women for sports and recreation, it could be that a seemingly innocuous choice of clothing (or a choice based on fashion, predicted performance advantage, or, in some cases, mandatory athletic uniforms) may have inadvertent negative consequences - such as a negative cycle of poorer motor performance, poorer motor learning, and decreased motivation for future engagement.

The present study examined the influence of athletic clothing style and body awareness on visual-motor performance in women. Specifically, participants completed a visual-motor aiming task while wearing tight and revealing (experimental) or loose and concealing (control) athletic clothing, and the spatiotemporal characteristics of their performance was assessed. The chosen aiming task allowed for quantification of several aspects of motor performance, including motor planning, action execution, and decision-making (risk taking vs. avoidance; Neyedli \& Welsh, 2013, 2014; Trommershäuser, Maloney, \& Landy, 2003a, 2003b). It was expected that women wearing tight and revealing athletic clothing would feel less comfortable and more aware of their bodies relative to the women wearing loose and concealing athletic clothing (Bell, Cardello, \& Schutz, 2003, 2005; Fredrickson et al., 1998). If this increase in body awareness reduces performance on motor tasks that demand cognitive resources, women wearing tight and revealing athletic clothing may demonstrate reduced motor performance and less optimal decision-making than the women wearing the loose and concealing clothing. A finding of no difference between the groups of women wearing tight compared with loose clothing would suggest that an increase in body awareness does not affect performance on cognitive-motor tasks. To partially preview results, although it was possible that the clothing and body awareness may have affected decision-making (similar to experience or level of reward; see Neyedli \& Welsh, 2013, 2015), no between-group differences were found in the decision-making data of the task. Hence, the reporting of the results and discussion will focus on the motor performance data.

\section{Method}

\section{Participants}

Participants were recruited from a large university community using convenience sampling procedures. Eligible participants were women between 18 and 35 years of age who could read and understand English and had normal or corrected-tonormal vision. The University of Toronto Research Ethics Board approved this study, and participants signed an informed consent form prior to completing the study. Data from 80 participants $\left(M_{\text {age }}=20.6\right.$ years, $S D_{\text {age }}=3.1$ years $)$ were analyzed. Because this was the first study to examine the effects of a clothing manipulation on motor performance, there was not a valid previous data set upon which to base a reliable sample size calculation. The only other study to come from our labs that used a between-subjects design for the visuo-motor performance task (Neyedli \& Welsh, 2015) had a sample size of 22, with $n=11$ in each of the two groups. For the present study, a sample size of $80(n=40$ per group $)$ was chosen because it was anticipated that the effect of the clothing manipulation would be more subtle than that of the wealth manipulation in the previous study. Further, we chose this sample size to ensure sufficient power in potential multiple regression analyses (with $n=20$ per variable). Participants were randomly assigned to the tight and revealing (TR) or 
the loose and concealing (LC) clothing group with the constraint that there be an equal number of participants in each group by the end of the study ( $n=40$ per group).

\section{Procedure}

Participants completed all tasks and survey measures during individual testing sessions in a lab at the university athletic centre. The experimenter was one of two cisgender women of a similar age to the participants ( 27 and 29 years of age, respectively). Participants were masked to the purpose of the study and were told that they were volunteering for a study examining "people's experiences wearing athletic clothing." Participants first provided informed consent and then completed a self-report demographics questionnaire and a series of questionnaires that assessed body-related perceptions ${ }^{1}$ (e.g., social anxiety related to body physique; see Table 1 for study workflow, including all measures).

Participants were then instructed by the experimenter to change into a set of athletic clothing in a dressing room. Athletic clothing was either (1) spandex shorts (7-inch rise, 5 -inch inseam) and a spandex tank top (TR clothing group), or (2) polyester basketball shorts (12-inch rise, 5 -inch inseam) and a cotton men's T-shirt (LC clothing group). Each item of clothing was black or dark blue, available in sizes XS to XL, and typical of clothing commonly worn in athletic settings (see Fig. 1). Neither set of clothing interfered with or restricted movement in any way. Participants chose the size of clothing that fit them best. The experimenter then took a digital picture of the participant wearing the clothing and recorded their anthropometric measurements (see Priming: Body Awareness in Materials section below for details). Participants then performed a body-size distortion task followed by the visualmotor aiming task (see Priming: Body Awareness and Main Study Outcome: Visual-Motor Aiming Task in Materials section below for details). To heighten clothing and body awareness, participants completed the two computer-based tasks while sitting at a desk, in a room with a full-length mirror positioned to their right such that their body was constantly visible in their peripheral visual field. Following each visualmotor aiming experimental block, participants spent approximately 5 minutes completing surveys including measures of affective valence and arousal. Once the visual-motor aiming task was complete, participants answered a final set of surveys, including measures of perceived clothing comfort, awareness of the clothing, similarity of the clothing typically worn by participants in daily life, and a measure of bodyrelated perceptions. Results related to body-related perceptions are not reported here because these and other measures did not test the current study's hypotheses (these results will

\footnotetext{
${ }^{1}$ The measures of body-related perceptions did not differ significantly between groups.
}

be reported in a separate paper focusing on the relationship between body image, clothing, and affect). Finally, participants were given their financial compensation $(\$ 10.00 \mathrm{CAD} /$ hour $+\sim \$ 2.50 \mathrm{CAD}$ for performance on the visual-motor task), debriefed on the full purpose of the study, and given the option to exclude any or all of their data. All participants completed the study procedure in this order.

\section{Materials}

Priming: Body awareness In addition to the mirror that was present during task performance, participants' height, weight, and waist circumference were measured prior to the experimental visual-motor aiming task to prime awareness of the body. A stadiometer (Seca 217 Stadiometer for Mobile Height Measurement) was used to measure height and a digital scale (Omron HBF-516B Body Composition Monitor and Scale) was used to measure weight. Waist circumference was measured with a tape measure in accordance with the Canadian Guidelines for Body Weight Classification in Adults (Health Canada, 2015).

Participants also completed 10 trials of a computerized body-size distortion task (Gardner \& Boice, 2004). Participants sat at a table approximately $40 \mathrm{~cm}$ in front of a 22-in. ViewSonic LCD touch-screen monitor (resolution: $1,680 \times 1,050$ pixels). For each trial, each participant was presented with a horizontally distorted version of an image of herself wearing the athletic clothing. The distorted image was an actual image of the participant wearing the clothing they were assigned to wear that was stretched or compressed in the horizontal dimension at a predetermined level ranging between $\pm 20 \%$ and $\pm 30 \%$ too wide or too thin. The level of distortion differed between each trial (10 images were made using unique levels of distortion) and the order of presentation (level and direction of distortion) was maintained across participants. Using a two-button mouse, participants adjusted the width of the image by pressing the right or left button (to contract or stretch the image). Each button press changed the image by $1 \%$ per sec. Participants were instructed to make as many adjustments as necessary until they believed the image was an accurate representation of their actual body size. The average amount of end distortion present after the participant had adjusted the width of the image was used as a measure of perceived body image.

Main study outcome: Visual-motor aiming task Participants completed a visual-motor aiming task that assessed visualmotor performance and decision-making (Trommershäuser et al., 2003a, 2003b). Participants sat at the table approximately $40 \mathrm{~cm}$ in front of the touch-screen monitor with the index finger of their dominant hand on a keyboard button aligned with the center of the screen. During each trial, a $9 \mathrm{~mm} \times$ 
Table 1. Study workflow

\begin{tabular}{|c|c|c|}
\hline Step & Item & Relevant measures \\
\hline 1 & Consent & \\
\hline \multirow[t]{3}{*}{2} & Preexperiment measures & \\
\hline & a) Demographics questionnaire & \\
\hline & b) Body image & $\begin{array}{l}\text { - Trait Self-Objectification Questionnaire }{ }^{1} \\
\text { - Objectified Body Consciousness Scale: Surveillance scale, Shame scale } \\
\text { - Social Physique Anxiety Scale }\end{array}$ \\
\hline 3 & Change into athletic clothing & \\
\hline \multirow[t]{4}{*}{4} & Prime body awareness & \\
\hline & a) Picture taken of participant in clothing & \\
\hline & b) Anthropometrics & $\begin{array}{l}\text { - Weight } \\
\text { - Height } \\
\text { - Waist circumference }\end{array}$ \\
\hline & c) Completion of the computerized body distortion $\operatorname{task}^{4}$ & - Difference between perceived and actual body size ${ }^{4}$ \\
\hline 5 & Aiming task: Practice and Experimental Block 1 & \\
\hline \multirow[t]{3}{*}{6} & Postblock measures & \\
\hline & a) Manipulation check & - 4-item scale assessing attention to task \\
\hline & b) Affect & $\begin{array}{l}\text { - Feelings Scale } \\
\text { - Felt Arousal Scale }\end{array}$ \\
\hline 7 & Aiming task: Experimental Block 2 & \\
\hline \multirow[t]{3}{*}{8} & Postblock measures & \\
\hline & a) Manipulation check & - 4-item scale assessing attention to task \\
\hline & b) Affect & $\begin{array}{l}\text { - Feelings Scale } \\
\text { - Felt Arousal Scale }\end{array}$ \\
\hline \multirow[t]{4}{*}{9} & Postexperiment measures & \\
\hline & a) Body image & - Social Physique Anxiety Scale \\
\hline & b) Flow measure & - Flow State Scale: Concentration scale ${ }^{7}$ \\
\hline & c) Clothing & $\begin{array}{l}\text { - Comfort } \\
\text { - Awareness } \\
\text { - Similarity }\end{array}$ \\
\hline
\end{tabular}

Note. The workflow of study procedures and associated measures. Participants completed all postblock measures twice, once after the first block of experimental trials and again after the second block of experimental trials

${ }^{1}$ Noll and Fredrickson (1998)

${ }^{2}$ Mckinley and Hyde (1996)

${ }^{3}$ Hart, Leary, and Rejeski (n.d.)

${ }^{4}$ Gardner and Boice (2004)

${ }^{5}$ Hardy and Rejeski (1989)

${ }^{6}$ Svebak and Murgatroyd (1985)

${ }^{7}$ Jackson and Marsh (1996)

$9 \mathrm{~mm}$ white fixation cross appeared at the center of a black screen for 1,000 ms followed by the outline of a blue rectangle (115 mm width $\times 80 \mathrm{~mm}$ height). The rectangle indicated the area where a partially overlapping green target and red penalty circle would appear during testing (see Fig. 2). The targetpenalty configuration appeared at a random location within this rectangle $500 \mathrm{~ms}$ later and acted as the imperative cue to initiate a movement. Participants were instructed to aim towards a location on the screen that they believed would maximize the amount of points they would receive.
Points were awarded based on the area of the screen that was contacted (i.e., movement end point). Contact with only the target circle yielded a small gain of 100 points and contact with only the penalty circle caused a large loss of 500 points. Contact with the overlapping area between the target and penalty resulted in a combined value of a loss of 400 points. If both the target and penalty circles were missed, participants received zero points. To encourage fast and ballistic responses, a time constraint was imposed. If participants failed to initiate their movement and touch the screen within a time 

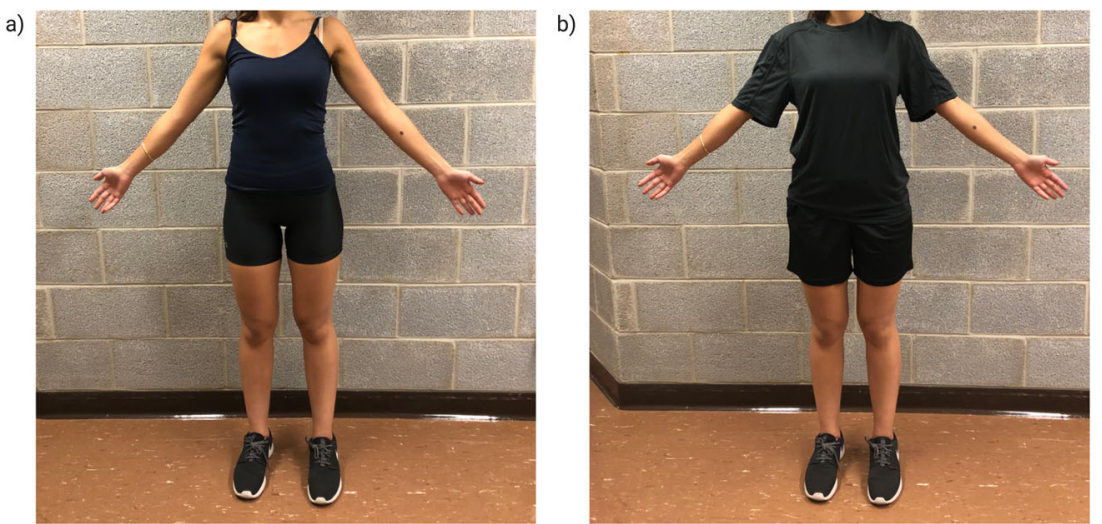

Fig. 1 Athletic clothing. Participants were randomly assigned to wear (a) tight and revealing or (b) loose and concealing athletic clothing

constraint ( $<850 \mathrm{~ms}), 700$ points were lost. At the end of the study, extra financial compensation was awarded to each participant according to the number of points earned (10 cents $\mathrm{CAD} / 100$ points). Thus, participants needed to decide on, select, and aim to the optimal movement end point to maximize financial gain by increasing the number of target "hits" while avoiding penalties (Neyedli \& Welsh, 2013; Trommershäuser et al., 2003a, 2003b).

During this visual-motor aiming stage of the study, participants first completed 20 single-target trials to familiarize themselves with the time constraint of the task. The time constraint decreased incrementally from $1,500 \mathrm{~ms}$ until it reached
$850 \mathrm{~ms}$. Then 50 practice and two blocks of 50 experimental trials were completed (see Fig. 2). Practice trials differed from experimental trials in that only the target circle appeared on the screen during practice trials, whereas experimental trials had both target and penalty regions.

For each participant, reaction time (RT) and movement time (MT) were calculated for each of the 50 practice trials and two blocks of 50 experimental trials. RT was the time interval from the moment the target appeared until the moment the finger released the keyboard. MT was measured from the moment the finger released the key until the participant touched the screen. To assess the spatial characteristics

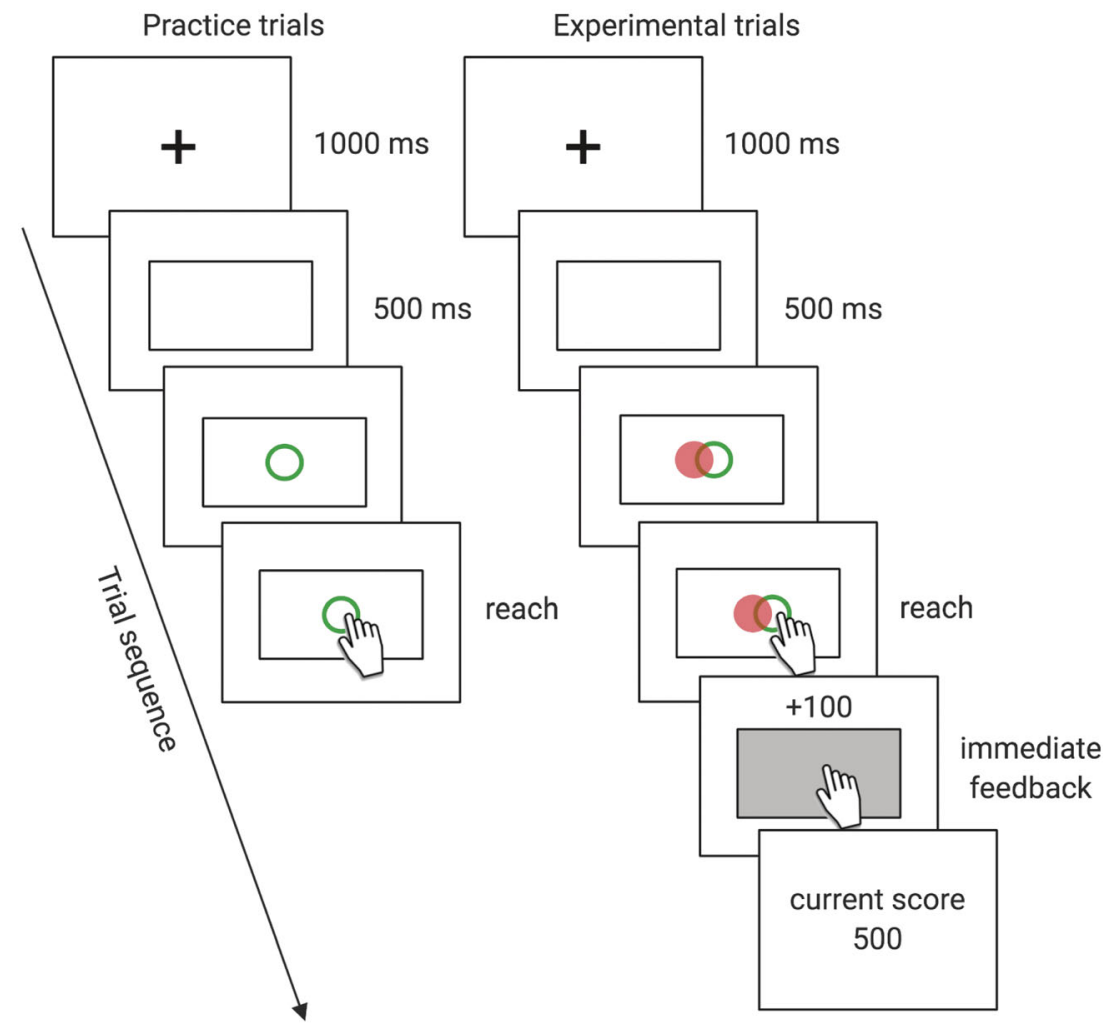

Fig. 2 Visual-motor aiming task. Participants completed 50 practice trials (left) followed by two blocks of 50 experimental trials (right). Open circles represent the target region, and solid circles represent the penalty region 
of the movement, variability in end-point position (variable error; VE) in the $x$ (horizontal) direction was calculated. VE is the standard deviation of the end points. End-point position from target center was also calculated. Because the penalty region appeared equally likely to the right and left of the target, absolute constant error (ACE) was calculated as the absolute difference (in $\mathrm{mm}$ ) between end-point position in the $x$ dimension and the target center. Number of points awarded (score) was also analyzed as a measure of task success. Optimal end point for maximizing gain and the difference between the actual end-point position relative to optimal end point during experimental trials was also calculated for each participant, but these values are not reported herein because there were no group differences in these measures of decision-making and performance.

Posttask clothing perceptions Perceived comfort and awareness of the athletic clothing was assessed because these clothing characteristics have previously been associated with women's focus towards their bodies (Bell et al., 2003, 2005; de Bruin \& Oudejans, 2018). An assessment of the similarity of the clothing to the clothing typically worn by participants was also performed to ensure participants were not accustomed to wearing the clothing outside of athletic contexts. To determine clothing comfort, participants were asked to rate "how comfortable the athletic clothing made you feel" using a 5-point Likert-type scale that ranged from 1 (very uncomfortable) through 3 (neutral) to 5 (very comfortable). For clothing awareness, participants were asked to rate "how aware were you of the clothing while wearing them" using a scale from 1 (very unaware) through 3 (neutral) to 5 (very aware). For similarity of clothing, they were asked to rate "how similar were the clothing you were wearing to the clothing you typically spend time in" using a scale from 1 (very not similar) through 3 (neutral) to 5 (very similar).

Data reduction and analysis Analyses were performed using $\mathrm{R}$ software for statistical computing and graphics (Version 1.1.463; R Core Team, 2019). Model assumptions for all analyses were tested. In instances of violation of the assumption of normality, nonparametric analyses were performed. First, potential group differences in perceived clothing comfort and awareness, and clothing similarity were determined between the TR and LC clothing groups using Mann-WhitneyWilcoxon $U$ tests. The influence of athletic clothing style on motor performance during the experimental condition of the aiming task was then investigated. Prior to these main analyses, experimental trials with an end point in any dimension (i.e., $x$ or $y$ ), RT, or MT 2.5 standard deviations above or below the participant-specific mean were excluded (Block 1 $M_{\text {excluded }}=5.58 \%$ of trials; Block $2 M_{\text {excluded }}=5.88 \%$ of trials). Time out trials (>850 ms) were not excluded from the analysis. Motor performance on the remaining trials of the experimental condition was assessed using the mean and standard deviation of RT and MT, as well as mean ACE, VE, and score. These values were submitted to separate 2 (Group: TR, LC) by 2 (Block: 1, 2) mixed-factorial ANOVA, where Group was the between-subjects factor and Block was the withinsubjects factor. Post hoc analysis of any significant effects was conducted using Tukey's HSD. Finally, for measures of motor performance that differed significantly between the TR and LC groups during experimental blocks, regression modelling was used to assess their relation with clothing characteristics (i.e., perceived comfort, awareness, and similarity) that also differed significantly between groups. Alpha was set at 0.05 for all analyses.

\section{Results}

Demographic data and preliminary analyses No participants opted to exclude any or all of their questionnaire or performance data from the current analyses. The groups did not differ in demographic characteristics ( $p$ s $>.20$; see Table 2). On average, both groups underestimated their body-image size during the body distortion task and the level of underestimation did not differ between groups $\left(M_{\mathrm{LC}}=-11.12 \% ; M_{\mathrm{TR}}\right.$ $=-9.92 \%), t(78)=0.88, p=0.38, d=0.20$.

The Mann-Whitney-Wilcoxon $U$ test on clothing comfort indicated that the LC group perceived their clothing to be significantly more comfortable than the TR group $\left(M_{\mathrm{LC}}=4\right.$; $\left.M_{\mathrm{TR}}=3.38 ; U=569, p=.02, r=.26\right)$. No significant differences were found between the groups in their awareness of their clothing $\left(M_{\mathrm{LC}}=2.53 ; M_{\mathrm{TR}}=2.63 ; U=834, p=.78, r=\right.$ $.04)$ or the similarity of the clothing to their regular clothing $\left(M_{\mathrm{LC}}=2.43 ; M_{\mathrm{TR}}=2.08 ; U=625, p=.14, r=.17\right)$.

\section{Main analysis: Motor performance during experimental trials} The analyses of the goal and the spatial measures of performance did not reveal any statistically significant effects for Group, Block, or Group $\times$ Block interactions $(p s \geq 0.10$; see Table 3 in the Appendix). Overall, these analyses suggest that the clothing worn by the participants did not impact the spatial characteristics of the movements or the resulting accumulation in points.

The temporal measures of performance included mean RT and MT as well as the variability of RT and MT. For mean RT, there were no significant main effects of Group, $F(1,78)=$ $0.88, p=.35, \eta_{\mathrm{p}}{ }^{2}=0.01$, or Block, $F(1,78)=1.73, p=.19, \eta_{\mathrm{p}}{ }^{2}$ $<0.01$. The interaction between Group and Block was also not statistically significant, $F(1,78)=0.5, p=.48, \eta_{\mathrm{p}}{ }^{2}<0.01$. For RT standard deviation, there was a significant effect of Block, whereby participants demonstrated higher variability during Block $2(M=49.4 \mathrm{~ms}, S D=16)$ relative to Block $1(M=$ $42.1 \mathrm{~ms}, S D=13), F(1,78)=19.85, p<.01, \eta_{\mathrm{p}}{ }^{2}=0.06$. The main effect of Group, $F(1,78)=1.25, p=0.27, \eta_{\mathrm{p}}{ }^{2}=0.01$, 
Table 2. Participant demographic characteristics

\begin{tabular}{|c|c|c|c|}
\hline Variable & $\begin{array}{l}\text { TR group } \\
n=40\end{array}$ & $\begin{array}{l}\text { LC group } \\
n=40\end{array}$ & $p$ \\
\hline \multicolumn{4}{|l|}{ Age (years) } \\
\hline $\begin{array}{l}\text { Mean }(S D) \\
\text { Range }\end{array}$ & $\begin{array}{l}20.65(3.37) \\
18-35\end{array}$ & $\begin{array}{l}20.55(2.78) \\
18-29\end{array}$ & 0.97 \\
\hline \multicolumn{4}{|l|}{ Highest level of education } \\
\hline $\begin{array}{l}\text { No high school } \\
\text { High school diploma or equivalent }\end{array}$ & $\begin{array}{l}0 \\
16\end{array}$ & $\begin{array}{l}0 \\
20\end{array}$ & 0.64 \\
\hline Some postsecondary & 9 & 7 & \\
\hline College diploma or certification & 1 & 0 & \\
\hline Undergraduate degree & 12 & 10 & \\
\hline Postgraduate degree & 2 & 3 & \\
\hline \multicolumn{4}{|l|}{ Marital status ${ }^{\mathrm{a}}$} \\
\hline $\begin{array}{l}\text { Single } \\
\text { Married or living together }\end{array}$ & $\begin{array}{l}38 \\
2\end{array}$ & $\begin{array}{l}37 \\
3\end{array}$ & 0.65 \\
\hline \multicolumn{4}{|l|}{ Cultural and racial background ${ }^{\mathrm{b}}$} \\
\hline White & 15 & 14 & 0.36 \\
\hline \multicolumn{4}{|l|}{ Primary language spoken at home ${ }^{c}$} \\
\hline \multicolumn{3}{|l|}{ Body Mass Index $\left(\mathrm{kg} / \mathrm{m}^{2}\right)$} & 0.78 \\
\hline $\begin{array}{l}\text { Mean }(S D) \\
\text { Range }\end{array}$ & $\begin{array}{l}22.56(3.66) \\
17.07-32.79\end{array}$ & $\begin{array}{l}22.53(3.28) \\
15.57-30.20\end{array}$ & 0.68 \\
\hline
\end{tabular}

Note. Demographic characteristics for the tight and revealing (TR) and loose and concealing (LC) clothing groups. Participants most often indicated their background as White $(n=29 ; 36 \%)$, primary language as English $(n=55 ; 69 \%)$, highest level of education as high school diploma or equivalent $(n=36 ; 45 \%)$, and marital status as single $(n=75 ; 94 \%)$

${ }^{a}$ Marital status endorsed most often. Selection included single, married, or living with a life partner, separated, divorced, widowed

${ }^{\mathrm{b}}$ Cultural and racial background endorsed most often. Selection included White, Chinese, South Asian, Black, Filipino, Latin American, Southeast Asian, Arab, West Asian, Japanese, Korean, Other

${ }^{\mathrm{c}}$ Primary language endorsed most often. Selection included English, French, Arabic, Chinese, Cree, Punjabi, Dutch, Hungarian, Italian, Korean, Portuguese, Tagalog, Ukrainian, Vietnamese, Persian, Spanish, German, Greek, Hindi, Russian, Tamil, Other

and the interaction between Group and Block, $F(1,78)=0.06$, $p=0.81, \eta \mathrm{p}^{2}<0.01$, were not statistically significant in RT variability. Thus, the processes leading to response initiation did not differ between clothing groups.

The analysis of mean MT revealed a significant main effect of Block, in which participants demonstrated decreased mean MT from Block $1(M=406 \mathrm{~ms}, S D=51)$ to Block $2(M=395$ $\mathrm{ms}, S D=52), F(1,78)=8.87, p<.01, \eta_{\mathrm{p}}{ }^{2}=0.10$. Although there was no significant main effect of Group, $F(1,78)=2.77$, $p=0.1, \eta_{\mathrm{p}}{ }^{2}=0.03$, there was a significant interaction between Group and Block for mean MT, $F(1,78)=6.35, p=.01, \eta_{\mathrm{p}}{ }^{2}=$ 0.075 (see Fig. 3a). Post hoc analysis of the interaction using Tukey's HSD $(p<.05$, critical value $=13.8 \mathrm{~ms})$ indicated that the LC group decreased their MTs from Block 1 to Block 2, whereas the TR group did not. Further, while MTs for the LC
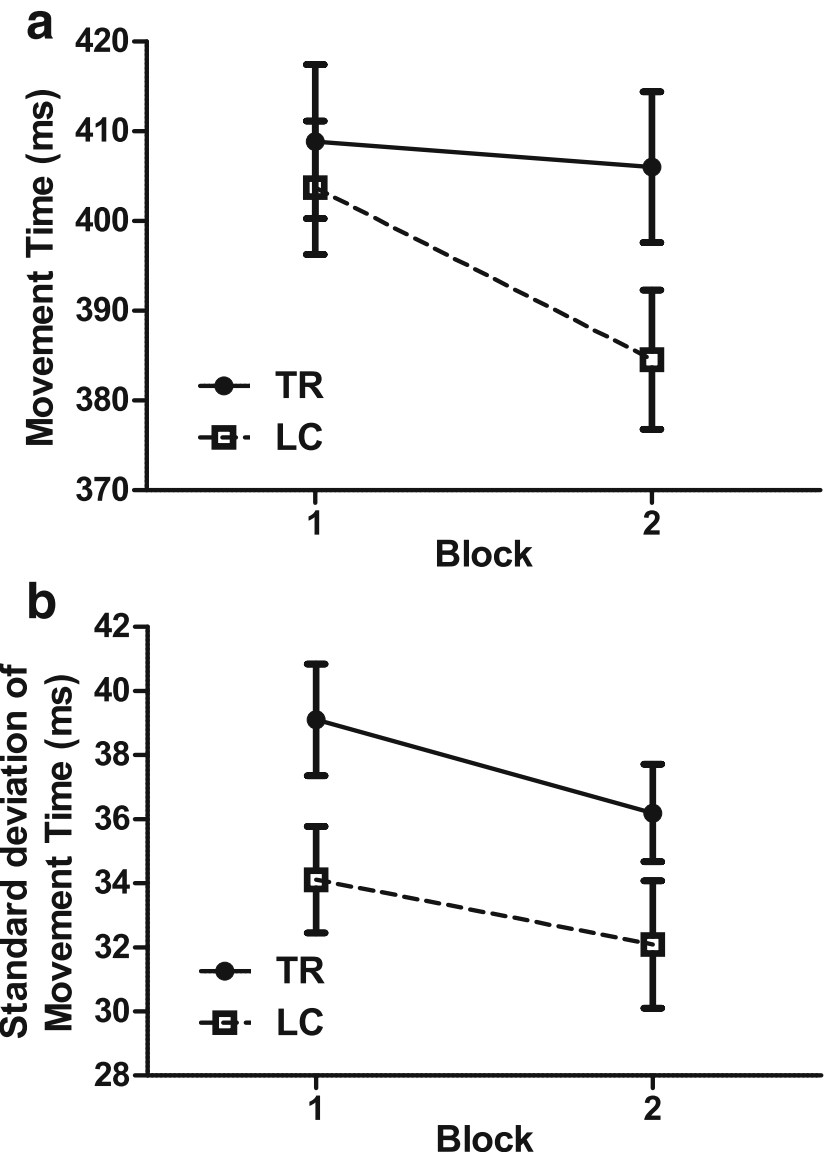

Fig. 3 a Movement time and (b) standard deviation of movement time during experimental blocks of the visual-motor task for the tight and revealing (TR) and the loose and concealing (LC) clothing groups. Error bars represent standard error of the mean

group were not different from those of the TR group in Block 1, mean MTs for the LC group were statistically lower than those for the TR group in Block 2. Analysis of MT standard deviation revealed that the variability of MT differed significantly between groups, with the TR group ( $M=37.64 \mathrm{~ms}, S D$ $=8.65$ ) demonstrating higher variability than the LC clothing group ( $M=33.10 \mathrm{~ms}, S D=10.27)$ - main effect for Group, $F(1,78)=7.62, p=.01, \eta_{\mathrm{p}}{ }^{2}=0.07$ (see Fig. 3b). A main effect of Block was also found, whereby participants demonstrated a decrease in MT standard deviation from Block $1(M$ $=36.6 \mathrm{~ms}, S D=11)$ to Block $2(M=34.1 \mathrm{~ms}, S D=11), F(1$, $78)=3.98, p=.05, \eta_{\mathrm{p}}{ }^{2}=0.01$. No significant interaction between Group and Block was found, $F(1,78)=0.02, p=$ $.89, \eta_{\mathrm{p}}{ }^{2}<0.01$ (see Fig. $3 \mathrm{~b}$ ). See Table 4 in the Appendix for descriptive statistics for measures of motor performance. Overall, the results of this analysis revealed that the participants wearing the tight and revealing clothing executed their movements with greater variability than the group wearing the loose and concealing clothing. Further, the LC group positively adapted their movement times (executed more efficient movements) with experience, whereas the TR group did not. 
Relation between clothing comfort and motor performance Recall that, although there was no between-group difference in perceived body size on the body distortion task, there was a significant effect of Group on perceived clothing comfort as well as a significant effect of Group in MT standard deviation and a significant interaction effect of Group and Block on mean MT during experimental blocks. To determine if there was a significant association between perceived clothing comfort and these measures of performance, separate correlations were conducted between perceived comfort and mean MT and MT standard deviation. Perceived clothing comfort did not predict mean MT, $F(2,157)=1.47, r^{2}=.01, p=.23$, nor MT standard deviation, $F(2,157)=2.73, r^{2}=.02, p=.07$.

\section{Discussion}

The present study evaluated the influence of tight and revealing versus loose and concealing athletic clothing on motor performance in women. This study was motivated by previous research that demonstrated that tight and revealing clothing can cause women to focus more on their bodies relative to external tasks, leading to poorer performance on cognitive tasks (Fredrickson et al., 1998; Hebl et al., 2004; Quinn et al., 2006). Consistent with the previous literature on cognitive performance, the results provide novel evidence that the style of women's athletic clothing influences perceived clothing comfort and motor performance.

First, we demonstrate that women perceive tight and revealing athletic clothing to be less comfortable than loose and concealing athletic clothing. This result is consistent with the notion that tight and revealing clothing might raise body awareness of the wearer. Indeed, tight and revealing athletic clothing has previously been identified as a key contextual element associated with women's heightened body awareness and negative perceptions of their body during performance, including among women athletes (de Bruin \& Oudejans, 2018; Price \& Pettijohn, 2006). Interestingly, the clothing did not affect perceived body size as measured by the Body Distortion Task. Further research is needed to explore potential mechanisms, including physical self-perceptions, that link clothing comfort and performance outcomes.

Second, the study revealed that tight and revealing athletic clothing can hinder efficient motor performance. Efficient motor planning and control is achieved when spatial accuracy and consistency is attained within short reaction and movement times (see Elliott et al., 2017, for review). In the present study, there were similar levels of spatial accuracy, spatial precision, and goal achievement across the clothing groups (no group differences in ACE, VE, and score). The time taken to achieve the same spatial and reward goals were longer and more variable in the group wearing the tight and revealing clothes than the group wearing the loose and concealing clothes. Thus, the same spatial goals were achieved less efficiently in the group wearing the tight and revealing clothes than the group wearing the loose and concealing clothing. Further, the Group $\times$ Block interaction for mean MT revealed that only the group wearing the loose and concealing clothes improved their performance across blocks. Thus, the tight and revealing group also did not learn or adapt their movement efficiency with more experience with the task. Given these findings and previous explanations of cognitive deficits for women wearing revealing clothing, it is likely that the tight and revealing athletic clothing directed resources away from motor planning and control processes leading to less efficient motor planning and adaptation in women during visual-motor performance.

To elucidate, it is plausible that the tight and revealing clothing produced slower and more variable MTs by shifting women's focus towards their bodies and away from the task. Indeed, body awareness has previously been associated with clothing style (Fredrickson et al., 1998; Quinn et al., 2006), and women's evaluations of their bodies are highly interconnected with clothing (Frith \& Gleeson, 2008). It is interesting that perceived clothing comfort differed between clothing styles, but was not associated with MT. Perceived clothing (dis)comfort has been previously shown to impair visualmotor RT and cognitive performance by shifting focus away from the task at hand (Bell et al., 2003, 2005). Here, it is likely that clothing comfort impacted resources for motor execution and motor planning. Future research will need to more fully examine the mechanisms behind the differences in perceived clothing comfort and MT between styles of athletic clothing in women primed to focus on their bodies.

In the bigger picture, the relation between body awareness and performance may be particularly salient in athletic contexts. During athletic activities it is often acceptable that women's appearance and bodily comportment be discussed and assessed by observers, and their bodies can be focused on over performance (Cameron, 2015). Women and girls are aware of this gaze and assessment of their appearance, particularly by men, which can contribute to anxiety (Cameron, 2015; Cockburn \& Clark, 2002). Indeed, girls are more aware of their bodies, such as their body shape, than are boys in athletic contexts (Slater \& Tiggermann, 2011). To perform optimally in athletic activities, one must focus on the movements and skills required. When women's focus is placed on their appearance, cognitive resources are likely divided between motor performance and their bodies. These negative performance and psychosocial responses may in turn prove demotivating for further athletic performance and learning. Given the wide variety of athletic clothing available to women for sport and recreation, this study highlights the importance of considering the impact style of clothing has on performance and explores the possible effect awareness of the body has on this relationship. 
Acknowledgements This research was supported by grants from the Social Sciences and Humanities Research Council (C.M.S., T.N.W.) and Natural Sciences and Engineering Research Council (H.F.N., T.N.W.). We would like to thank Amy Nesbitt, Saba Taravati, and Dr. Shea Balish for their contributions to make this study possible, and all participants who took part in this work. C.M.S. holds a Canada Research Chair in Physical Activity and Mental Health.

\section{Appendix}

Table 3. The results of the ANOVAs for the analyses of the spatial characteristics of movement and goal achievement during experimental blocks

\begin{tabular}{lllll}
\hline Variable & $d f$ & $F$ & $p$ & $\mathrm{n}_{\mathrm{p}}{ }^{2}$ \\
\hline Mean VE $\mathrm{x}$ & & & & \\
Group & 1,78 & 0.03 & .87 & $<0.01$ \\
Block & 1,78 & 1.43 & .24 & $<0.01$ \\
Group $\times$ Block & 1,78 & 0.19 & .87 & $<0.01$ \\
Mean ACE & & & & \\
Group & 1,78 & $<0.01$ & .98 & $<0.01$ \\
Block & 1,78 & 2.91 & .10 & $<0.01$ \\
Group $\times$ Block & 1,78 & 0.08 & .77 & $<0.01$ \\
Mean score & & & & \\
Group & 1,78 & 1.53 & .22 & 0.02 \\
Block & 1,78 & $<0.01$ & .96 & $<0.01$ \\
Group $\times$ Block & 1,78 & 0.05 & .83 & $<0.01$ \\
\end{tabular}

Note. The effect of group, the effect of block, and the interaction effect of group and block are shown. $\mathrm{VE}_{\mathrm{x}}=$ variable error $x$ dimension; $\mathrm{ACE}_{\mathrm{x}}=$ absolute constant error $x$ dimension
Data availability statement The data sets analyzed during the current study are available from the corresponding author on reasonable request. Open practice statement None of the data or materials for the experiment reported here is available, and the experiment was not preregistered. 
Table 4. Descriptive statistics for measures of motor performance during experimental blocks

\begin{tabular}{|c|c|c|c|c|}
\hline \multirow[t]{2}{*}{ Variable and task block } & \multicolumn{2}{|l|}{ Mean $(S D)$} & \multicolumn{2}{|l|}{ Range } \\
\hline & TR & $\mathrm{LC}$ & TR & $\mathrm{LC}$ \\
\hline \multicolumn{5}{|l|}{ Mean $\mathrm{VE}_{\mathrm{x}}$} \\
\hline Block 1 & $4.73(3.57)$ & $4.83(3.25)$ & $2.09-7.04$ & $3.39-6.88$ \\
\hline Block 2 & $4.62(3.30)$ & $4.77(3.48)$ & $2.62-7.09$ & $3.16-7.64$ \\
\hline \multicolumn{5}{|l|}{ Mean $\mathrm{ACE}_{\mathrm{x}}$} \\
\hline Block 1 & $4.26(3.44)$ & $4.33(3.16)$ & $2.03-6.65$ & $3.04-6.45$ \\
\hline Block 2 & $4.12(3.19)$ & $4.22(3.19)$ & $2.27-6.70$ & $2.88-6.66$ \\
\hline \multicolumn{5}{|l|}{ Mean score } \\
\hline Block 1 & $1,972.5(3,434.44)$ & $2,080(2,493.40)$ & $-16,500-4600$ & $-8,700-4,600$ \\
\hline Block 2 & $1,927.5(3,255.92)$ & 2097.5 (2945.79) & $-11,500-4,700$ & $-10,200-4,700$ \\
\hline \multicolumn{5}{|l|}{ Mean RT } \\
\hline Block 1 & $300.00(30.00)$ & $300.00(40.00)$ & $240.00-350.00$ & $220.00-390.00$ \\
\hline Block 2 & $300.00(30.00)$ & $300.00(40.00)$ & $200.00-360.00$ & $240.00-350.00$ \\
\hline \multicolumn{5}{|l|}{$S D \mathrm{RT}$} \\
\hline Block 1 & $40.00(10.00)$ & $40.00(10.00)$ & $30.00-90.00$ & $30.00-80.00$ \\
\hline Block 2 & $50.00(20.00)$ & $50.00(20.00)$ & $30.00-10.00$ & $30.00-80.00$ \\
\hline \multicolumn{5}{|l|}{ Mean MT } \\
\hline Block 1 & $410.00(50.00)$ & $400.00(50.00)$ & $290.00-520.00$ & $310.00-480.00$ \\
\hline Block 2 & $410.00(50.00)$ & $380.00(50.00)$ & $290.00-510.00$ & $290.00-480.00$ \\
\hline \multicolumn{5}{|l|}{$S D \mathrm{MT}$} \\
\hline Block 1 & $40.00(10.00)$ & $30.00(10.00)$ & $20.00-80.00$ & $20.00-60.00$ \\
\hline Block 2 & $40.00(10.00)$ & $30.00(10.00)$ & $20.00-80.00$ & $20.00-80.00$ \\
\hline
\end{tabular}

Note. Descriptive statistics for measures of motor performance during experimental blocks of the visual-motor aiming task by clothing group. Values are in presented in seconds. $S D=$ standard deviation; $\mathrm{TR}=$ tight and revealing clothing group; $\mathrm{LC}=$ loose and concealing clothing group; $\mathrm{RT}=$ reaction time; $\mathrm{MT}=$ movement time; $\mathrm{VE}_{\mathrm{x}}=$ variable error $x$ dimension; $\mathrm{ACE}_{\mathrm{x}}=$ absolute constant error $x$ dimension. $\mathrm{RT}$ and MT values are presented in milliseconds, score values are presented as number of points awarded, $\mathrm{VE}_{\mathrm{x}}$ and $\mathrm{ACE}_{\mathrm{x}}$ values are presented in millimeters

\section{References}

Bell, R., Cardello, A. V., \& Schutz, H. G. (2003). Relations among comfort of fabrics, ratings of comfort, and visual vigilance. Perceptual and Motor Skills, 97(1), 57-67. https://doi.org/10. 2466/pms.2003.97.1.57

Bell, R., Cardello, A. V., \& Schutz, H. G. (2005). Relationship between perceived clothing comfort and exam performance. Family and Consumer Sciences Research Journal, 33(4), 308-320. doi:https:// doi.org/10.1177/1077727X04274115

Cameron, C. (2015). Dedicated athletes, deviant women: The experience of being an amateur sportswoman in a contemporary Canadian context (Master's thesis, Carleton University). doi:https://doi.org/ $10.22215 /$ etd/2015-11180

Cockburn, C., \& Clarke, G. (2002). "Everybody's looking at you!”: Girls negotiating the "femininity deficit" they incur in physical education. Women's Studies International Forum, 25(6), 651-665. doi:https:// doi.org/10.1016/S0277-5395(02)00351-5

de Bruin, A. P., \& Oudejans, R. R. D. (2018). Athletes' body talk: The role of contextual body image in eating disorders as seen through the eyes of elite women athletes. Journal of Clinical Sport Psychology, 12(4), 675-698. doi:https://doi.org/10.1123/jcsp.2018-0047
Elliott, D., Lyons, J., Hayes, S. J., Burkitt, J. J., Roberts, J. W., Grierson, L. E., ... Bennett, S. J. (2017). The multiple process model of goaldirected reaching revisited. Neuroscience \& Biobehavioral Reviews, 72, 95-110.

Fredrickson, B. L., \& Harrison, K. (2005). Throwing like a girl: Selfobjectification predicts adolescent girls' motor performance. Journal of Sport and Social Issues, 29(1), 79-101. doi:https://doi. org/10.1177/0193723504269878

Fredrickson, B. L., Roberts, T.-A., Noll, S. M., Quinn, D. M., \& Twenge, J. M. (1998). That swimsuit becomes you: Sex differences in selfobjectification, restrained eating, and math performance. Journal of Personality and Social Psychology, 75(1), 269-284. doi:https://doi. org/10.1037//0022-3514.75.1.269

Frith, H., \& Gleeson, K. (2008). Dressing the body: The role of clothing in sustaining body pride and managing body distress. Qualitative Research in Psychology, 5(4), 249-264. doi:https://doi.org/10.1080/ 14780880701752950

Gardner, R. M., \& Boice, R. (2004). A computer program for measuring body size distortion and body dissatisfaction. Behavior Research Methods, Instruments, \& Computers, 36(1), 89-95. doi:https://doi. org/10.3758/BF03195553 
Gay, R. K., \& Castano, E. (2010). My body or my mind: The impact of state and trait objectification on women's cognitive resources. European Journal of Social Psychology, 40(5), 695-703. doi: https://doi.org/10.1002/ejsp.731

Gervais, S. J., Vescio, T. K., \& Allen, J. (2011). When what you see is what you get: The consequences of the objectifying gaze for women and men. Psychology of Women Quarterly, 35(1), 5-17. doi:https:// doi.org/10.1177/0361684310386121

Guthold, R., Stevens, G. A., Riley, L. M., \& Bull, F. C. (2018). Worldwide trends in insufficient physical activity from 2001 to 2016: A pooled analysis of 358 population-based surveys with 1.9 million participants. The Lancet Global Health, 6(10), e1077e1086. doi:https://doi.org/10.1016/S2214-109X(18)30357-7

Hardy, C. J., \& Rejeski, W. J. (1989). Not what, but how one feels: The measurement of affect during exercise. Journal of Sport and Exercise Psychology, 11(3), 304-317. doi:https://doi.org/10.1123/ jsep.11.3.3040

Hart, E. A., Leary, M. R., \& Rejeski, W. J. (n.d.). The measurement of social physique anxiety. Journal of Sport \& Exercise Psychology, 11(1), 94-104. doi:https://doi.org/10.1123/jsep.11.1.94

Health Canada. (2015). Canadian guidelines for body weight classification in adults. Retrieved from the Government of Canada website: https://www.canada.ca/en/health-canada/services/food-nutrition/ healthy-eating/healthy-weights/canadian-guidelines-body-weightclassification-adults.html

Hebl, M. R., King, E. B., \& Lin, J. (2004). The swimsuit becomes us all: ethnicity, gender, and vulnerability to self-objectification. Personality and Social Psychology Bulletin, 30(10), 1322-1331. doi:https://doi.org/10.1177/0146167204264052

Hommel, B., Chapman, C. S., Cisek, P., Neyedli, H. F., Song, J.-H., \& Welsh, T. N. (2019). No one knows what attention is. Attention, Perception, \& Psychophysics doi:https://doi.org/10.3758/s13414019-01846-w

Jackson, S. A., \& Marsh, H. W. (1996). Development and validation of a scale to measure optimal experience: The Flow State Scale. Journal of Sport and Exercise Psychology, 18(1), 17-35. doi:https://doi.org/ 10.1123/jsep.18.1.17

Kahalon, R., Shnabel, N., \& Becker, J. C. (2018). Experimental studies on state self-objectification: A review and an integrative process model. Frontiers in Psychology, 9. doi:https://doi.org/10.3389/ fpsyg.2018.01268

Mckinley, N. M., \& Hyde, J. S. (1996). The objectified body consciousness scale: Development and validation. Psychology of Women Quarterly, 20(2), 181-215. doi:https://doi.org/10.1111/j.14716402.1996.tb00467.x

Melbye, L., Tenenbaum, G., \& Eklund, R. (2007). Self-objectification and exercise behaviors: The mediating role of social physique anxiety. Journal of Applied Biobehavioral Research, 12(3/4), 196-220. doi:https://doi.org/10.1111/j.1751-9861.2008.00021.x

Neyedli, H. F., \& Welsh, T. N. (2013). Optimal weighting of costs and probabilities in a risky motor decision-making task requires experience. Journal of Experimental Psychology: Human Perception and Performance, 39(3), 638-645. doi:https://doi.org/10.1037/ a0030518
Neyedli, H. F., \& Welsh, T. N. (2014). People are better at maximizing expected gain in a manual aiming task with rapidly changing probabilities than with rapidly changing payoffs. Journal of Neurophysiology, 111(5), 1016-1026. doi:https://doi.org/10.1152/ jn.00163.2013n

Neyedli, H. F., \& Welsh, T. N. (2015). Experience and net worth affects optimality in a motor decision task. Motor Control, 19, 75-89. doi: https://doi.org/10.1123/mc.2013-0024

Noll, S. M., \& Fredrickson, B. L. (1998). A mediational model linking self-objectification, body shame, and disordered eating. Psychology of Women Quarterly, 22(4), 623-636. doi:https://doi.org/10.1111/j. 1471-6402.1998.tb00181.x

Parsons, E. M., \& Betz, N. E. (2001). The relationship of participation in sports and physical activity to body objectification, instrumentality, and locus of control among young women. Psychology of Women Quarterly, 25(3), 209-222. doi:https://doi.org/10.1111/1471-6402. 00022

Price, B. R., \& Pettijohn, T. R., II. (2006). The effect of ballet dance attire on self-perceptions of female dancers. Social Behavior and Personality, 34(8), 991-998. doi:https://doi.org/10.2224/sbp.2006. 34.8.991

Quinn, D. M., Kallen, R. W., Twenge, J. M., \& Fredrickson, B. L. (2006). The disruptive effect of self-objectification on performance. Psychology of Women Quarterly, 30(1), 59-64. doi:https://doi.org/ 10.1111/j.1471-6402.2006.00262.x

R Core Team. (2019). R: A language and environment for statistical computing [Computer software]. Vienna, Austria: R Foundation for Statistical Computing. Retrieved from https://www.R-project. org/

Slater, A., \& Tiggemann, M. (2011). Gender differences in adolescent sport participation, teasing, self-objectification and body image concerns. Journal of Adolescence, 34(3), 455-463. doi:https://doi.org/ 10.1016/j.adolescence.2010.06.007

Svebak, S., \& Murgatroyd, S. (1985). Metamotivational dominance: A multimethod validation of reversal theory constructs. Journal of Personality and Social Psychology, 48(1), 107-116. doi:https:// doi.org/10.1037/0022-3514.48.1.107

Trommershäuser, J., Maloney, L. T., \& Landy, M. (2003a). Statistical decision theory and trade-offs in the control of motor response. Spatial Vision, 16(3), 255-275. doi:https://doi.org/10.1163/ 156856803322467527

Trommershäuser, J., Maloney, L. T., \& Landy, M. (2003b). Statistical decision theory and the selection of rapid, goal-directed movements. Journal of the Optical Society of America, 20(7), 1419. doi:https:// doi.org/10.1364/JOSAA.20.001419

Wulf, G. (2013). Attentional focus and motor learning: a review of 15 years. International Review of Sport and Exercise Psychology, 6(1), 77-104. doi:https://doi.org/10.1080/1750984X.2012.723728

Publisher's note Springer Nature remains neutral with regard to jurisdictional claims in published maps and institutional affiliations. 